\title{
Some Observations on the Absorption and Excretion of 4:6-Dinitro-o-cresol
}

\author{
2. THE ELIMINATION OF, 4:6-DINITRO-o-CRESOL BY MAN AND BY ANIMALS
}

\author{
BY E. KING AND D. G. HARVEY \\ Department for Research in Industrial Medicine, Medical Research Council, \\ M.R.C. Laboratories, Hampstead, and the London Hospital, E. 1 .
}

(Received 17 May 1952)

Harvey, Bidstrup \& Bonnell (1951) have shown that 4:6-dinitro-o-cresol (DNOC) accumulates in man as the result of small daily doses and have shown that DNOC is very slowly eliminated from the body. This observation has received support from the evidence of a clinical case of a seriously poisoned spray operator reported by Pollard \& Filbee (1951).

A preliminary account of the work reported in this paper was given at a meeting of the Biochemical Society (King \& Harvey, 1952).

In the first paper of this series (King \& Harvey, 1953) attention has been drawn to the marked species differences between man, the rat and the rabbit in their ability to accumulate DNOC. A study of the relative capacities for eliminating DNOC illustrates still further the quantitative differences in the response of these species towards DNOC.

The present communication has three main objects. First, to record methods for comparing the capacity possessed by man, the rat and the rabbit for eliminating DNOC. Secondly; to investigate the urinary excretion of DNOC. Thirdly, to discuss the problem of DNOC storage in the body in the light of clinical observations (Pollard \& Filbee, 1951; Steer, 1951) and experimental evidence (Parker, Barnes \& Denz, 1951):

\section{EXPERIMENTAL METHODS}

The experiments described were carried out with the technical assistance of Miss Jean Peal and Mr K. E. Carling, and embody similar methods and techniques to those described by King \& Harvey (1953).

The capacity for eliminating DNOC from the body was studied by measuring the rate of decay of the concentration of DNOC in the blood following one or more doses at different levels. Blood DNOC estimations were made daily for man and the rat, but at more frequent (3-6 hr.) intervals for the rabbit. Groups of four to six hooded rats and Himalayan rabbits were used for each experiment. The excretion of urinary DNOC was also studied, but no attempt was made to identify or estimate any metabolites of DNOC (Smith, Smithies \& Williams, 1952).

Blood volumes of the human volunteers (Harvey et al. 1951) were calculated by the method of Gibson \& Evans (1937).

\section{RESULTS}

These are given in Figs. 1 and 2 and in Tables 1-4. Pollard \& Filbee (1951) have suggested that the decay rate of DNOC from the blood of the spray operator may be exponential. This has now been verified and a value calculated for the slope. This is shown on Fig. 1, together with a histogram of his daily urinary DNOC excretion, and the scatter of the daily DNOC values of the human volunteers (Harvey et al. 1951) obtained during the post-dosing period.

Regression lines expressing the decay in the blood DNOC values of man, rat and rabbit are shown in Fig. 2. The regression lines were computed from the data given in Table 1. In all cases the decay was exponential. Table 2 compares the urinary output of DNOC of man, the rat and the rabbit following a single dose of DNOC.

Table 3 gives an analysis of the disposal of a single dose of DNOC in man as accountable and nonaccountable fractions; less than $40 \%$ of a single dose of $75 \mathrm{mg}$. can be accounted for after $24 \mathrm{hr}$.

In some early experiments Mr J. W. Roe, formerly of this department, obtained evidence to suggest that DNOC was bound to the plasma albumin. This was checked by adding about $10 \mu \mathrm{g}: / \mathrm{g}$. DNOC to human plasma and carrying out an electrophoretic separation. Analysis of the fractions indicated that more than $95 \%$ of the added DNOC was located in the albumin fraction.

\section{Statistical treatment of results}

Analysis of variance of the times and blood levels of DNOC of the several groups of animals was carried out and the appropriate slopes and halftimes calculated therefrom. An example of a typical analysis, namely, that of the six rabbits given a single dose of $30 \mathrm{mg} . / \mathrm{kg}$. by stomach tube, is given in Table 4.

\section{DISCUSSION}

The results of the experiments show that man has relatively inefficient mechanisms for dealing with DNOC. On the other hand, the rat and the rabbit 


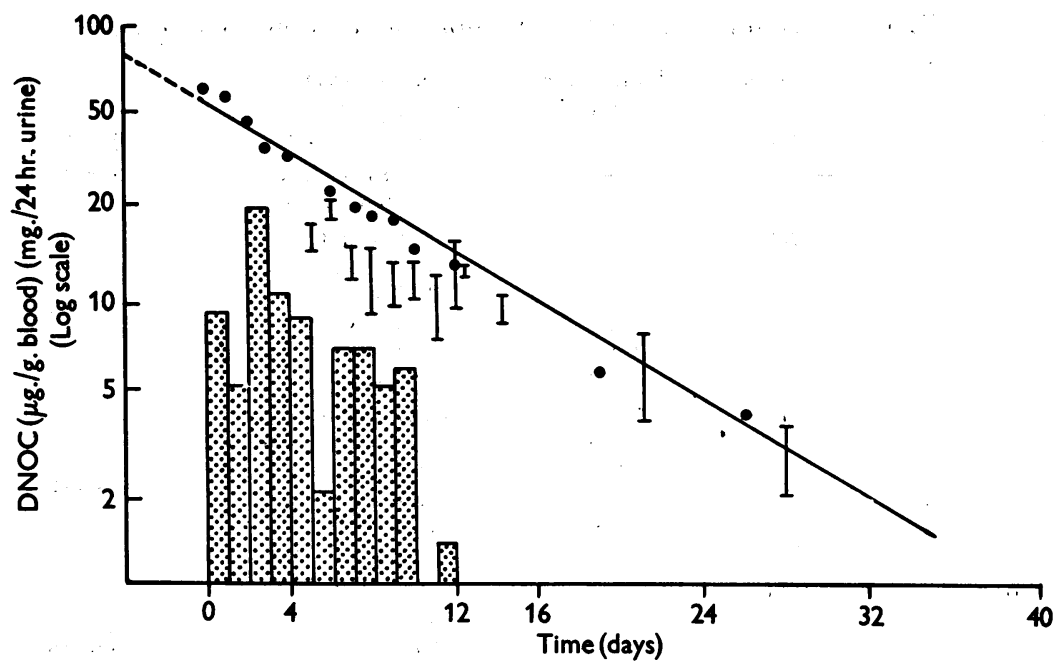

Fig. 1. Decay curve of blood DNOC of spray operator (O) (Pollard \& Filbee, 1951), and scatter values of human volunteers (I) (Harvey et al. 1951). Spray operator's $24 \mathrm{hr}$. urine DNOC shown as histogram.

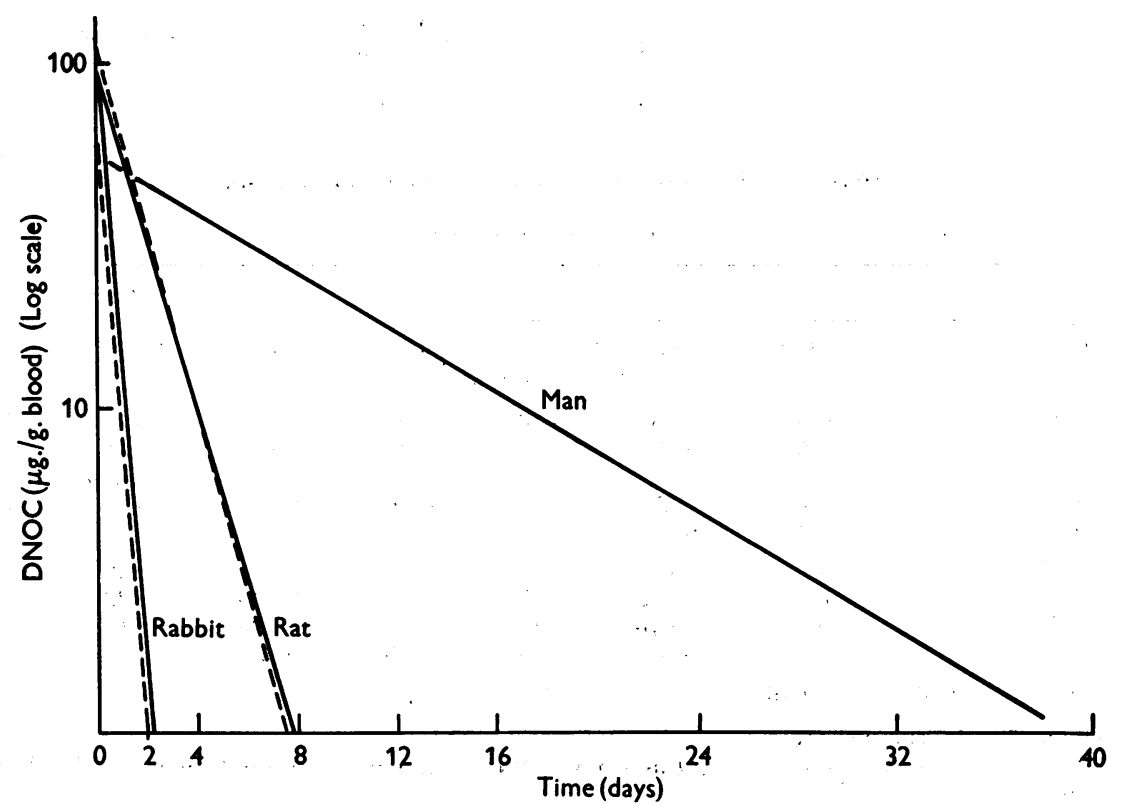

Fig. 2. Decay curves of blood DNOC of man, the rat and the rabbit. Continuous lines represent curves resulting from many doses, broken lines from a single dose. The curves are derived from the data given in Tables 1 and 4.

appear to be capable of dealing with large doses very centrations have dropped to levels of about $5 \mu \mathrm{g} . / \mathrm{g}$. efficiently. Comparison of the values for the blood. or less the subsequent decay curve will be much DNOC levels of the volunteers $A, B, C, D$ and $E$ (Harvey et al. 1951) with those of the spray operator (Pollard \& Filbee, 1951) indicates that there is a good measure of agreement between the two groups of values, and that a single exponential curve is applicable to a wide range of values. However, there is a suggestion that once blood DNOC conshallower and possibly less regular. This is illustrated by the observation that on the 28th day after the last dose the average blood DNOC value of the volunteer subjects was $2.5 \mu \mathrm{g}$./g. whereas on the 47 th day it was $1.0 \mu \mathrm{g}$./g. This slope is obviously much shallower than that calculated for the higher values, as shown in Fig. 1. This suggests that very 
Table 1. Decaying blood DNOC values in man and in animals

\begin{tabular}{|c|c|c|c|c|c|}
\hline $\begin{array}{l}\text { Species, } \\
\text { number and sex }\end{array}$ & $\begin{array}{l}\text { Daily dose } \\
\text { of DNOC } \\
\text { (mg./kg.) }\end{array}$ & $\begin{array}{l}\text { Time after } \\
\text { dosing } \\
\text { (hr.) }\end{array}$ & $\begin{array}{c}\text { Blood DNOC } \\
(\mu \mathrm{g} \cdot / \mathrm{g} .) \\
\operatorname{Mean} \pm \text { s.e. }\end{array}$ & Slope $(b)$ & $\begin{array}{l}\text { Half-time } \\
\text { (hr.) }\end{array}$ \\
\hline $\operatorname{Man}(1)$ & - & - & $\begin{array}{c}\text { See Pollard \& } \\
\text { Filbee, } 1951\end{array}$ & -0.002 & $153 \cdot 6$ \\
\hline Rat (F.) (4) & $9 \times 20$ & $\begin{array}{r}6 \cdot 0 \\
24 \cdot 0 \\
48 \cdot 0 \\
72 \cdot 0 \\
120 \cdot 0 \\
144 \cdot 0\end{array}$ & $\left.\begin{array}{r}72 \cdot 2 \pm 10 \cdot 0 \\
50 \cdot 7 \pm 7 \cdot 5 \\
23 \cdot 7 \pm 4 \cdot 9 \\
17 \cdot 1 \pm 3 \cdot 3 \\
7 \cdot 1 \pm 1 \cdot 5 \\
2 \cdot 0 \pm 0.5\end{array}\right\}$ & -0.0105 & 26.8 \\
\hline Rat (F.) (5) & $1 \times 30$ & $\begin{array}{r}3 \cdot 5 \\
24 \cdot 0 \\
46 \cdot 5 \\
72 \cdot 0 \\
\mathbf{7 7 \cdot 0} \\
\mathbf{9 5 \cdot 0}\end{array}$ & $\left.\begin{array}{c}105 \cdot 0 \pm 10 \cdot 0 \\
64 \cdot 6 \pm 4 \cdot 8 \\
32 \cdot 5 \pm 4 \cdot 0 \\
19 \cdot 3 \pm 2 \cdot 7 \\
13 \cdot 9 \pm 1 \cdot 7 \\
11 \cdot 2 \pm 2 \cdot 1\end{array}\right\}$ & -0.0112 & $28 \cdot 5$ \\
\hline Rabbit (F.) (6) & $9 \times 25$ & $\begin{array}{r}4.5 \\
7.5 \\
10.5 \\
24 \cdot 0 \\
48 \cdot 0\end{array}$ & $\left.\begin{array}{c}54 \cdot 7 \pm 6 \cdot 6 \\
44 \cdot 4 \pm 5 \cdot 3 \\
31 \cdot 2 \pm 3 \cdot 1 \\
6 \cdot 1 \pm 1 \cdot 07 \\
0 \cdot 7 \pm 0 \cdot 2\end{array}\right\}$ & -0.0448 & 6.7 \\
\hline Rabbit (F.) (6) & $1 \times 30$ & $\begin{array}{r}6 \cdot 0 \\
9 \cdot 0 \\
12 \cdot 0 \\
25 \cdot 0 \\
31 \cdot 0 \\
49 \cdot 0\end{array}$ & $\left.\begin{array}{r}49 \cdot 5 \pm 3 \cdot 4 \\
46 \cdot 8 \pm 2 \cdot 9 \\
30 \cdot 9 \pm 2 \cdot 4 \\
7 \cdot 7 \pm 1 \cdot 3 \\
4 \cdot 2 \pm 1 \cdot 0 \\
0 \cdot 8 \pm 0 \cdot 3\end{array}\right\}$ & -0.0454 & $6 \cdot 6$ \\
\hline
\end{tabular}

Table 2. Urinary excretion of DNOC by animals

Hours after dosing

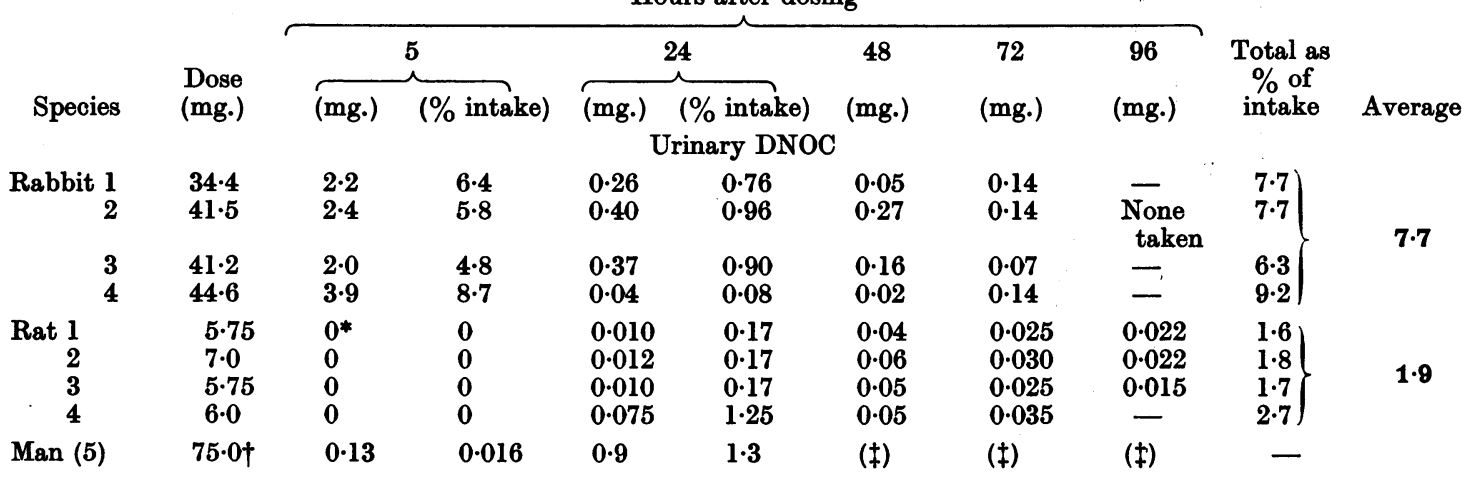

* No urine voided during this period.

$\dagger$ Over 13 days from the first day of dosing these five volunteer subjects excreted about $7.0 \%$ of the total DNOC intake $(500-700 \mathrm{mg}$.).

$\ddagger$ No values available.

Table 3. Distribution of DNOC in man following single dose of $75 \mathrm{mg} . \mathrm{DNOC}$

\begin{tabular}{|c|c|c|c|c|c|c|}
\hline \multirow{3}{*}{$\begin{array}{l}\text { Volunteer } \\
\text { subject. }\end{array}$} & \multirow{3}{*}{$\begin{array}{c}\text { Blood } \\
\text { volume } \\
\text { (ml.) }\end{array}$} & \multicolumn{4}{|c|}{ Accountable DNOC $24 \mathrm{hr}$. after dose } & \multirow{3}{*}{$\begin{array}{l}\text { DNOC which } \\
\text { cannot be } \\
\text { accounted for } \\
(\% \text { intake })\end{array}$} \\
\hline & & \multicolumn{2}{|c|}{ In blood } & \multicolumn{2}{|c|}{ In urine } & \\
\hline & & (mg.) & (\% intake) & (mg.) & (\% intake) & \\
\hline $\begin{array}{l}A \\
B \\
C \\
D \\
E\end{array}$ & $\begin{array}{l}\mathbf{5 2 0 0} \\
\mathbf{5 4 0 0} \\
\mathbf{5 8 0 0} \\
\mathbf{5 6 0 0} \\
\mathbf{6 0 0 0}\end{array}$ & $\begin{array}{l}28 \cdot 7 \cdot \\
30 \cdot 3 \\
35 \cdot 0 \\
26 \cdot 4 \\
28 \cdot 7\end{array}$ & $\begin{array}{l}38 \cdot 2 \\
40 \cdot 4 \\
46 \cdot 6 \\
35 \cdot 2 \\
35 \cdot 5\end{array}$ & $\begin{array}{l}0.8 \\
0.6 \\
1.3 \\
0.6 \\
1.5\end{array}$ & $\begin{array}{l}1 \cdot 1 \\
0.80 \\
1 \cdot 7 \\
0.80 \\
2.00\end{array}$ & $\begin{array}{l}60 \cdot 7 \\
58 \cdot 8 \\
51 \cdot 7 \\
64 \cdot 0 \\
62 \cdot 5\end{array}$ \\
\hline
\end{tabular}


Table 4. Analysis of variance of blood DNOC decay of six rabbits following single $30 \mathrm{mg} . / \mathrm{kg}$. dose

Times of
sampling
(hr.)
$4 \cdot 5$
$\mathbf{7 \cdot 5}$
$10 \cdot 5$
$24 \cdot 0$
$48 \cdot 0$

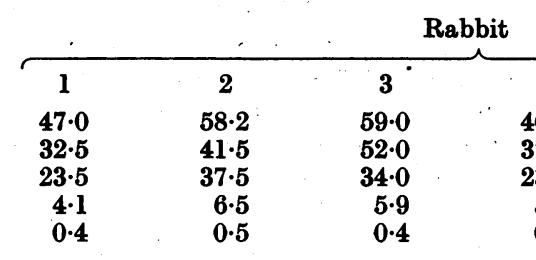

Sum of
squares
$16 \cdot 545649$
$16 \cdot 585030$

$0 \cdot 060619$
$1 \cdot 022477$
$17 \cdot 668126$

4
$40 \cdot 0$
$37 \cdot 5$
$23 \cdot 0$
$5 \cdot 6$
$0 \cdot 6$

$\begin{gathered}\text { Degrees of } \\ \text { freedom }\end{gathered}$
5
1
4
30
35

$\begin{array}{cc}5 & 6 \\ 83 \cdot 0 & 31 \cdot 0 \\ 67 \cdot 0 & 36 \cdot 0 \\ 41 \cdot 5 & 27 \cdot 5 \\ 9 \cdot 3 & 5 \cdot 3 \\ 1 \cdot 2 & 1 \cdot 3\end{array}$

Mean
square
$3 \cdot 329130$
$16 \cdot 585030$

0.015155
0.034082
-

$\begin{array}{cc}\begin{array}{c}\text { Variance } \\ \text { of ratio }\end{array} & \\ (F) & P \\ 98 & <0.001 \\ 487 & <0.001 \\ 0.44 & >0.05 \\ - & -\end{array}$

Therefore the relation between the log concn. blood and time is linear. The slope $b$ is $-0 \cdot 0454$, and the half-time is $6 \cdot 6 \mathrm{hr}$.

small quantities of DNOC may be tolerated by man and possibly by animals without causing any undue harm. Comparison of these two main sets of values can only be made on general terms, since the human volunteers were engaged upon their normal occupations involving some exercise and the spray operator was a bed-rest patient during the time of investigation of his blood DNOC levels.

Harvey et al. (1951) have demonstrated that exercise, amongst other deviations from normal routine, will tend to alter the blood DNOC levels giving them false high values. Undoubtedly this is one cause of the scatter of the values of the human volunteers. The difference in the quantitative response towards DNOC exhibited by man, the rat and the rabbit is remarkable, and the decay curves of Fig. 2 fully illustrate this. An additional point of interest and possibly significance is that within wide limits repeated daily doses do not appear to affect the animals' capacity for eliminating DNOC (Fig. 2).

The general similarity of the decay of the two groups of blood DNOC values following dosing, i.e. the spray operator on a large number of doses and the volunteer subjects on a limited number suggests that man probably behaves in a similar qualitative manner to the rat and the rabbit in that his detoxicating and excretory mechanisms are relatively unimpaired.

Comparison of the three species with respect to the excretion of urinary DNOC shows that in the rabbit about $5-8 \%$ of the intake appears in the urine within the first $5 \mathrm{hr}$., and that thereafter the amount excreted is very small, possibly $1 \%$, over several days. Smith et al. (1952) have drawn attention to the fact that only $20 \%$ of a single dose of DNOC administered to a rabbit can be recovered as DNOC and its metabolites within $48 \mathrm{hr}$. of dosing, thereby suggesting that there is destruction of the molecule into small and not readily identifiable components. The rat appears to occupy an intermediate position between man and rabbit and the percentage of DNOC excreted is of the same order per day as the amount excreted by man. This suggests that the degree of detoxication must be greater in the rat since the blood DNOC curves are so very different. Examination of the urinary DNOC values of the spray operator shows that there is a possible trend towards an exponential decay which would appear to be a little steeper than the blood decay curve. The fact that there are several values which appear to fall very far off the apparent curve suggests that further observations will be necessary before the nature and slope of the urinary decay curve can be firmly established.

The accumulation of DNOC in man could be explained in two ways: first, that detoxication and excretion are very slow; or secondly, that there is some store of DNOC in the body. The value of the decay curve of DNOC for man lends support to the hypothesis that detoxication and excretion are inefficient and slow. The evidence that the rat does not readily store DNOC has been supported by the work of Parker et al. (1951), who have shown that the tissues of rats which have been given repeated doses of DNOC do not contain significant quantities of the substance. That man behaves in a similar manner is shown by the observations of Steer (1951), who demonstrated that the tissues of a fatal case of DNOC poisoning contained no more than $5 \mu \mathrm{g}$./g. of DNOC and many $1 \mu \mathrm{g}$. or less. It is possible that both these velues can be accounted for by the presence of DNOC in the residual blood of the tissues. Thus it seems that any internal store of DNOC will be temporary and not permanent to any degree. Another curious observation relevant to the problem of storage is that the necropsy findings reported by Steer, showed that $24 \mathrm{hr}$. after death the 
synovial fluid contained $44 \mu \mathrm{g}$./g. of DNOC. Further, the spray operator reported by Pollard \& Filbee (1951) had a value of about $0 \cdot 9 \mu \mathrm{g}$. DNOC/ml. of cerebrospinal fluid. Preliminary investigations suggest that once DNOC has entered the blood it is attached to the albumin fraction. It seems very likely, therefore, that the chief internal stores of DNOC in the body are the extracellular fluids containing albumin. Examination of the accountable and non-accountable DNOC in the body $24 \mathrm{hr}$. after dosing shows that only about $40 \%$ can be accounted for in the blood and in the urine. There remains $60 \%$ which must include DNOC and its metabolites. The bulk of these are probably held by the albumin of the other extracellular fluids.

Regarding other stores of DNOC, attention must be drawn to the skin and to the hair. Men working with DNOC have.heavily.stained skins, particularly on the palmar and plantar surfaces and many have bright yellow hair. It is relatively easy to account for the staining of the skin but less easy to account for that of the hair; this may be due partly to excretion and partly to external contamination. The experiments of Harvey et al. (1952) and King \& Harvey (1953) suggest that although the skin may form a permanent reservoir for DNOC it is unlikely that a dose large enough to give fatal results will penetrate. It seems beyond doubt, therefore, that although the keratins of the external epidermal tissues -may prove to be 'binders' of DNOC, the internal albumins are of much greater practical and physiological significance.
The marked quantitative response towards DNOC exhibited by the three species studied in the two communications of this series emphasizes the need for careful and accurate interpretation of results obtained on experimental animals when it is the ultimate object to apply them to man (cf. Brit. med. J. 1951).

The slow excretion of DNOC by man emphasizes the need for the institution and maintenance of adequate protective measures in order that exposure to, and absorption of, DNOC will be reduced to a safe minimum (King \& Harvey, 1953).

\section{SUMMARY}

1. The blood 4:6-dinitro-o-cresol (DNOC) decay curves have been studied in man, the rat and the rabbit.

2. The ability to eliminate DNOC appears to be in the order rabbit $>$ rat $>$ man.

3. The storage of DNOC is discussed, and it is suggested that the extracellular fluids are the principal internal stores of DNOC because albumin links with DNOC.

The authors wish to thank Dr D. Hunter, Head of the Department, for encouragement; Dr P. L. Bidstrup and Dr J. A. L. Bonnell for valuable discussions; Dr W. L..M. Perry for statistical advice; Dr C. Steer, Dr R. V. Young and Dr M. Long for post-mortem samples; Dr R. A. Kekwick for carrying out an electrophoretic separation of plasma and Miss A. Mackrill for assistance with the experimental animals.

\title{
. REFERENCES
}

Brit. med. $J$. (1951). 1, 628. Toxic chemicals in agriculture. Gibson, J. G. \& Evans, W. A. (1937). J. clin. Invest. 16, 317. Harvey, D. G., Bidstrup, P. L.. \& Bonnell, J.'A. L. (1951). Brit. med. J. 2, 14.

King, E. \& Harvey, D. G..(1952), Biochem. J. 51, vii.

King, E. \& Harvey, D. G. (1953).. Biochem. J. 53, 185.
Parker, V. H., Bàrnes, J. M. \& Denz, F. (1951). Brit. J. industr. Med. 8, 226.

Pollard, A. B. \& Filbee, J. F. (1951). Lancet, 2, 618.

Smith, J. N., Smithies, R. H. \& Williams, R. T. (1952). Biochem. J. 50, xxxvii.

Steer, C. (1951). Lancet, 1, 1419.

\section{The Identification of Coumarins and Related Compounds by Filter-paper Chromatography}

\author{
BY T. SWAIN \\ Low Temperature. Station for Research in Biochemistry and Biophysics, University of Cambridge, \\ and Department of Scientific.and Industrial Research
}

(Received 5 June 1952)

The need for a method of identifying small amounts of coumarins and related. blue-fluorescing compounds became evident. during the course of an investigation on the naturally occurring polyphenolic compounds involved in enzymic browning by potato polyphenolase. Previous workers (Lewis \& Doty, 1948: Bowman \& Hanning, 1951) have reported that ethanolic extracts of the potato tuber have an intense blue fluorescence, and this has been borne out by -investigations carried out in this laboratory (Baruah \& Swain, unpublished observations). Furthermore, scopoletin has been isolated from'potato tubers taken from plants infected with leaf roll virus (Andreae, 1948), and has been shown 